\title{
Effect of Nitrogen Doping on the Photoluminescence of Amorphous Silicon Oxycarbide Films
}

\author{
Jie Song, Rui Huang, Yi Zhang, Zewen Lin, Wenxing Zhang *, Hongliang Li, Chao Song, \\ Yanqing Guo and Zhenxu Lin *
}

School of Materials Science and Engineering, Hanshan Normal University, Chaozhou 521041, China; songjie@hstc.edu.cn (J.S.); rhuang@hstc.edu.cn (R.H.); cavtor@126.com (Y.Z.); 2636@hstc.edu.cn (Z.L.); lhl4@hstc.edu.cn (H.L.); chaosong@hstc.edu.cn (C.S.); yqguo126@126.com (Y.G.)

* Correspondence: wenxingzhang@hstc.edu.cn (W.Z.); linzhenxu2013@163.com (Z.L.)

Received: 26 August 2019; Accepted: 26 September 2019; Published: 27 September 2019

\begin{abstract}
The effect of nitrogen doping on the photoluminescence (PL) of amorphous $\mathrm{SiC}_{\mathrm{x}} \mathrm{O}_{\mathrm{y}}$ films was investigated. An increase in the content of nitrogen in the films from $1.07 \%$ to $25.6 \%$ resulted in red, orange-yellow, white, and blue switching PL. Luminescence decay measurements showed an ultrafast decay dynamic with a lifetime of $\sim 1$ ns for all the nitrogen-doped $\mathrm{SiC}_{\mathrm{x}} \mathrm{O}_{\mathrm{y}}$ films. Nitrogen doping could also widen the bandgap of $\mathrm{SiC}_{\mathrm{x}} \mathrm{O}_{\mathrm{y}}$ films. The microstructure and the elemental compositions of the films were studied by obtaining their Raman spectra and their X-ray photoelectron spectroscopy, respectively. The PL characteristics combined with an analysis of the chemical bonds configurations present in the films suggested that the switching PL was attributed to the change in defect luminescent centers resulting from the chemical bond reconstruction as a function of nitrogen doping. Nitrogen doping provides an alternative route for designing and fabricating tunable and efficient $\mathrm{SiC}_{\mathrm{x}} \mathrm{O}_{\mathrm{y}}$-based luminescent films for the development of Si-based optoelectronic devices.
\end{abstract}

Keywords: photoluminescence; amorphous silicon oxycarbide; nitrogen doping; defect; plasma enhanced chemical vapor deposition

\section{Introduction}

Efficient silicon (Si)-based luminescent materials are indispensable components to realize a cheap and complementary metal oxide semiconductor (CMOS) optical integration. Thus far, different systems of $\mathrm{Si}$-based luminescent materials, such as $\mathrm{SiO}_{\mathrm{x}}, \mathrm{SiN}_{\mathrm{x}}, \mathrm{SiC}_{\mathrm{x}}$, and $\mathrm{SiN}_{\mathrm{x}} \mathrm{O}_{\mathrm{y}}$, have been developed, and efforts have been devoted to understanding and ameliorating the light emission of Si-based materials [1-9]. Silicon oxycarbide $\left(\mathrm{SiC}_{\mathrm{x}} \mathrm{O}_{\mathrm{y}}\right)$ has been widely explored because of its strong light emission and high solid solubility for rare earths [10-13]. $\mathrm{SiC}_{\mathrm{x}} \mathrm{O}_{\mathrm{y}}$ also features a tunable band gap. As such, it is beneficial to obtaining strong white electroluminescence at a low driving voltage in $\mathrm{SiC}_{\mathrm{x}} \mathrm{O}_{\mathrm{y}}$-based light-emitting diodes [14]. In the recent reference, Gallis et al. systematically studied the white photoluminescence (PL) dynamics from $\mathrm{SiC}_{\mathrm{x}} \mathrm{O}_{\mathrm{y}}$ film, where the band tail states related to the $\mathrm{Si}-\mathrm{O}-\mathrm{C}$ and/or the $\mathrm{Si}-\mathrm{C}$ bonds were suggested as the sources of the luminescence [11]. Recently, optical gain was demonstrated in $\mathrm{a}-\mathrm{SiC}_{\mathrm{x}} \mathrm{O}_{\mathrm{y}}$ under ultraviolet excitation, which was attributed to the formation of a three-level luminescence model with the intermediate level related to Si dangling bond (DB) defects radiative state [15]. Furthermore, an increase in $\mathrm{C}$ content in $\mathrm{SiC}_{\mathrm{x}} \mathrm{O}_{\mathrm{y}}$ films can cause a strong light emission ranging from near-infrared to orange regions [15]. Although performance is enhanced in $\mathrm{SiC}_{\mathrm{x}} \mathrm{O}_{\mathrm{y}}$ films, progress remains slow. The main obstacle lies in the fact that the light emission efficiency generally remains too low to allow the fabrication of efficient light-emitter devices. To date, studies on the effect of doping on the optical properties of $\mathrm{SiC}_{\mathrm{x}} \mathrm{O}_{\mathrm{y}}$ films have mainly focused 
on rare earth (RE) doping, such as Er and Eu doping [16-18]. However, up to now, the effect of other elements on the optical properties of $\mathrm{SiC}_{\mathrm{x}} \mathrm{O}_{\mathrm{y}}$ films is still unclear.

In this letter, the effect of nitrogen doping on the PL of amorphous $\mathrm{SiC}_{\mathrm{x}} \mathrm{O}_{\mathrm{y}}$ film was investigated. Interestingly, an increase in nitrogen content in the films induced strong red, orange-yellow, white, and blue switching PL. Combining the PL results with the analysis of the microstructure and the chemical bonding configurations within the films, it suggests that the rearrangement of chemical bonds with varying nitrogen plays an important role in the evolution of PL characteristics in the films.

\section{Materials and Methods}

Nitrogen-doped $\mathrm{SiC}_{\mathrm{x}} \mathrm{O}_{\mathrm{y}}$ films with the thickness of $550 \mathrm{~nm}$ were grown at $250{ }^{\circ} \mathrm{C}$ on $\mathrm{Si}$ substrates and quartz by radio frequency (RF) glow-discharge decomposition of $\mathrm{SiH}_{4}, \mathrm{CH}_{4}, \mathrm{O}_{2}$, and $\mathrm{NH}_{3}$ mixtures in the very high frequency plasma enhanced chemical vapor deposition (VHF-PECVD) system. The flow rates of $\mathrm{SiH}_{4}, \mathrm{CH}_{4}$, and $\mathrm{O}_{2}$ were kept at 3.5, 5, and $1.2 \mathrm{sccm}$, respectively, whereas the flow rate of $\mathrm{NH}_{3}$ varied from $0.5 \mathrm{sccm}$ to $5 \mathrm{sccm}$ to control the $\mathrm{N}$ content in the films. The films were named $\mathrm{S}_{\mathrm{x}}(\mathrm{x}=1,2$, $3,4)$ for the $\mathrm{NH}_{3}$ flow rates at $0.5,1,3$, and $5 \mathrm{sccm}$, respectively. The RF power and the deposition pressure for the growth were maintained at $30 \mathrm{~W}$ and $20 \mathrm{~Pa}$, respectively. The optical band gaps of the films were calculated using the Tauc method, which were determined by spectrophotometer (Shimadzu UV-3600, Shimadzu Corporation, Kyoto, Japan). The PL spectra of the films were measured at room temperature by use of a fluorescence spectrophotometer (Jobin Yvon fluorolog-3, Horiba, Ltd., Kyoto, Japan). Time resolved PL were measured by use of an Edinburgh FLS1000 spectrometer (Edinburgh Instruments Ltd., Livingston, UK) equipped with a $600 \mathrm{~mW} 375 \mathrm{~nm}$-laser beam with the repetition rate of $20 \mathrm{MHz}$. The microstructures of the films were characterized by Raman spectra. The chemical bonds of the films were examined by Fourier transform infrared (FTIR) absorption, and $\mathrm{Si}, \mathrm{O}, \mathrm{C}$, and $\mathrm{N}$ contents in the films were identified through $\mathrm{X}$-ray photoelectron spectroscopy.

\section{Results and Discussion}

Figure 1a shows the PL spectra of the SiCO:N films prepared at different $\mathrm{NH}_{3}$ flow rates. Strong visible light emission could be tuned from red to blue regions at room temperature by adjusting the $\mathrm{NH}_{3}$ flow rates increased from $0.5 \mathrm{sccm}$ to $5 \mathrm{sccm}$. Red, orange-yellow, white, and blue switching luminescence were strong enough to be seen with naked eyes even at $325 \mathrm{~nm}$ Xe lamp light excitation. Figure $1 \mathrm{~b}$ illustrates the optical band gap energy of the films as a function of the $\mathrm{NH}_{3}$ flow rate. The optical band gap $E_{\text {opt }}$ of the films was obtained in accordance with the Tauc plot Equation (1):

$$
(\alpha h v)^{1 / 2}=A^{1 / 2}\left(h v-E_{o p t}\right)
$$

where $\alpha$ is the absorption coefficient, $A$ is a coefficient quantifying the slope of the absorption edge, and $h v$ is the photon energy [19]. The calculated $E_{\text {opt }}$ increases linearly from $2.83 \mathrm{eV}$ to $3.66 \mathrm{eV}$ as the $\mathrm{NH}_{3}$ flow rate increases from $0.5 \mathrm{sccm}$ to $5 \mathrm{sccm}$. This finding demonstrates that $\mathrm{N}$ doping can widen the bandgap of $\mathrm{SiC}_{\mathrm{x}} \mathrm{O}_{\mathrm{y}}$ films, which may result from the substitution of stronger $\mathrm{Si}-\mathrm{N}$ bonds for weak $\mathrm{Si}-\mathrm{Si}$ bonds or $\mathrm{Si}-\mathrm{C}$ bonds. The comparison of PL with $E_{\text {opt }}$ results indicated that the value of PL peak energy of all the films was obviously smaller than the corresponding $E_{\text {opt }}$, suggesting that the origin of PL was not from the band-to-band recombination.

The microstructure of the SiCO:N films was examined using Raman spectra (Figure 2a) to further understand the origin of PL characteristics. All the SiCO:N films exhibited similar line shape characteristics typical of amorphous silicon-based materials. A broad Raman band, which was ascribed to the transverse optical (TO) vibration mode of amorphous silicon, peaked at $\sim 470 \mathrm{~cm}^{-1}$ for all the SiCO:N films. These results showed that all the SiCO:N films had a uniform amorphous structure without the presence of Si nanocrystals [20]. Furthermore, there was no obvious change in the surface morphology of the films prepared at different $\mathrm{NH}_{3}$ flow rates, as was revealed by atomic force microscopy (Figure 2b). 



Figure 1. (a) Photoluminescence (PL) spectra of the SiCO:N films prepared by different $\mathrm{NH}_{3}$ flow rates: $\mathrm{S} 1(0.5 \mathrm{sccm}), \mathrm{S} 2(1 \mathrm{sccm}), \mathrm{S} 3(3 \mathrm{sccm})$, and S4 $(5 \mathrm{sccm})$. The inset is the optical images of PL from the films under $325 \mathrm{~nm}$ Xe lamp light excitation. (b) The optical band gap of the SiCO:N films vs. the $\mathrm{NH}_{3}$ flow rates. The inset shows the $\left((\alpha h v)^{1 / 2} \cdot \mathrm{vs} \cdot h v\right)$ plot of the SiCO:N film $\mathrm{S}_{\mathrm{x}}(\mathrm{x}=1,2,3,4)$.
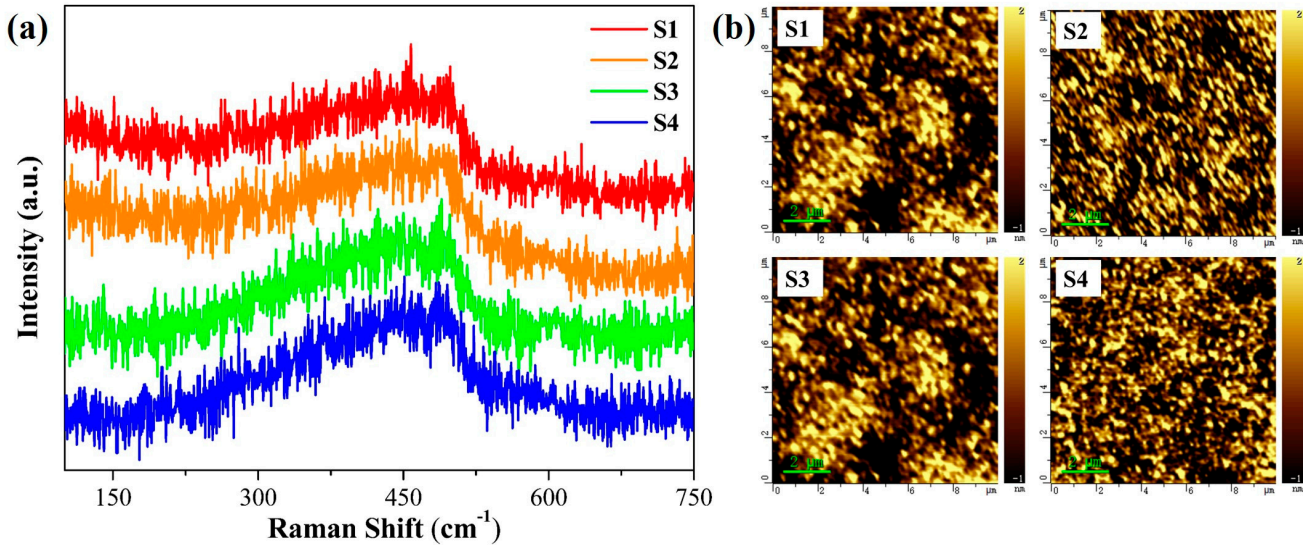

Figure 2. (a) Raman spectra of the SiCO: $\mathrm{N}$ films with various $\mathrm{NH}_{3}$ flow rates, (b) atomic force microscopic images of the $\mathrm{SiCO}: \mathrm{N}$ films prepared by different $\mathrm{NH}_{3}$ flow rates: $\mathrm{S} 1(0.5 \mathrm{sccm}), \mathrm{S} 2(1 \mathrm{sccm})$, S3 $(3 \mathrm{sccm})$, and S4 (5 sccm).

The films were measured by time-resolved PL to obtain further insights into the PL mechanism of the SiCO:N films (Figure 3). The decay curves could be fitted with a double exponential function:

$$
I(t)=A_{1} \exp \left(\frac{-t}{\tau_{1}}\right)+A_{2} \exp \left(\frac{-t}{\tau_{2}}\right)
$$

where $A_{\mathrm{i}}$ and $\tau_{\mathrm{i}}(\mathrm{i}=1,2)$ are the normalized amplitudes of the components and the time constants, respectively [21]. The obtained average lifetime of the SiCO:N films was about $1 \mathrm{~ns}$. The luminescent dynamic behavior was similar to that observed in defect-related luminescent Si-based materials, such as $\mathrm{SiN}_{\mathrm{x}} \mathrm{O}_{\mathrm{y}}$ and $\mathrm{SiC}_{\mathrm{x}} \mathrm{O}_{\mathrm{y}}[19,21]$. Furthermore, it was also found that the luminescence decay lifetimes in our case were shorter than those in the band-tail recombination model where a broader band-tail brought a longer lifetime, as the photogenerated carriers could be thermalized into deeper localized states [22]. Therefore, the results suggested that the light emission of the SiCO:N films originated from the defect luminescent centers in the films.

The FTIR spectra of the SiCO:N films were obtained to study the local bonding changes in the films grown at different $\mathrm{NH}_{3}$ flow rates (Figure 4). In the $\mathrm{S} 1 \mathrm{film}$, the vibration modes related to $\mathrm{Si}-\mathrm{C}, \mathrm{Si}-\mathrm{N}, \mathrm{C}-\mathrm{Si}-\mathrm{O}, \mathrm{Si}-\mathrm{H}$, and $\mathrm{C}-\mathrm{H}$ bonds could be clearly observed. The bands centered at 860 and $1039 \mathrm{~cm}^{-1}$ could be ascribed to $\mathrm{Si}-\mathrm{N}$ and $\mathrm{C}-\mathrm{Si}-\mathrm{O}$ stretching modes, respectively [23,24]. Additionally, a band at $1265 \mathrm{~cm}^{-1}$ was assigned to the $\mathrm{Si}-\mathrm{CH}_{3}$ stretching vibration [25]. A small band shoulder at 
$800 \mathrm{~cm}^{-1}$ was observed and was assigned to the Si-C stretching vibration [24]. A distinct absorption peak at $2170 \mathrm{~cm}^{-1}$ and a weak band located at $2965 \mathrm{~cm}^{-1}$ were attributed to the Si-H and the C-H stretching vibrations, respectively [26]. A weak band around $3375 \mathrm{~cm}^{-1}$ was associated with the N-H stretching mode [23]. The most important feature for the FTIR spectra was the strong dependence of major bands on $\mathrm{NH}_{3}$ flow rates. As the $\mathrm{NH}_{3}$ flow rates increased, the intensity of $\mathrm{C}-\mathrm{Si}-\mathrm{O}$ bonds gradually decreased, and the peak gradually became red shifted. As the $\mathrm{NH}_{3}$ flow rate increased to $3 \mathrm{sccm}$, this band broadened and red shifted to $\sim 1010 \mathrm{~cm}^{-1}$ with a shoulder at $\sim 940 \mathrm{~cm}^{-1}$, which was assigned to the $\mathrm{N}-\mathrm{Si}-\mathrm{O}$ vibration [27]. As the $\mathrm{NH}_{3}$ flow rate further increased to $5 \mathrm{sccm}$, the band of the $\mathrm{N}-\mathrm{Si}-\mathrm{O}$ vibration became dominant, indicating that the silicon oxycarbide-dominant phase of the film transformed into silicon oxynitride. Apparently, the increase in the $\mathrm{NH}_{3}$ flow rate resulted in chemical bond reconstruction in the films. Based on the FTIR spectra, the evolution of PL characteristics could be suggested from the chemical bond reconstruction in SiCO:N films.



Figure 3. Room temperature time resolved photoluminescence for the SiCO:N films with various $\mathrm{NH}_{3}$ flow rates.

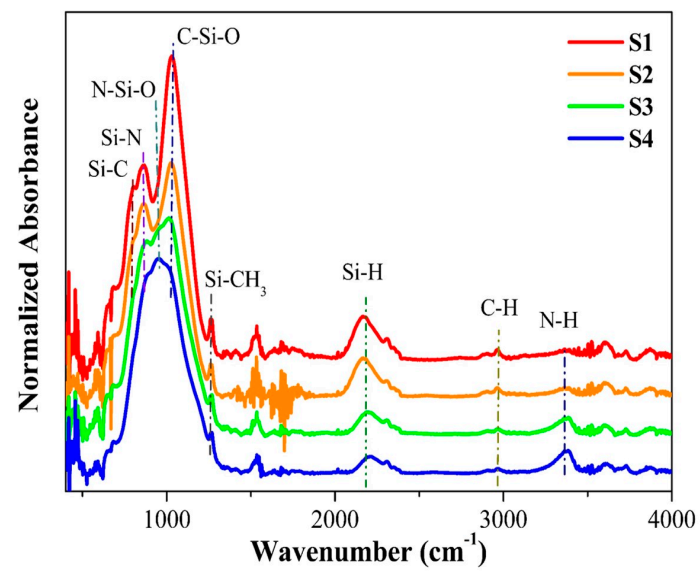

Figure 4. Fourier transform infrared (FTIR) spectra of the SiCO:N films grown at different $\mathrm{NH}_{3}$ flow rates. 
The composition of the SiCO:N films was examined through X-ray photoelectron spectroscopy (XPS) (Figure 5). The atomic percentages of $\mathrm{Si}, \mathrm{C}, \mathrm{O}$, and $\mathrm{N}$ in the SiCO:N film fabricated at an $\mathrm{NH}_{3}$ flow rate of $0.5 \mathrm{sccm}$ were $51.89 \%, 19.82 \%, 27.22 \%$, and $1.07 \%$, respectively. This finding indicated that the Si-rich silicon oxycarbide phase was dominant in the S1 film. The change in the XPS spectra was the gradual decrease in $\mathrm{Si}$ and $\mathrm{C}$ concentrations with the increase in $\mathrm{N}$ concentration and $\mathrm{NH}_{3}$ flow rates (Figure 5). As the $\mathrm{NH}_{3}$ flow rate increased to $5 \mathrm{sccm}$, the $\mathrm{N}$ concentration rapidly increased to $25.6 \%$, whereas the $\mathrm{Si}$ and the C concentrations decreased to $40.8 \%$ and $8.22 \%$, respectively. This finding was consistent with the observed results in the FTIR spectra shown in Figure 4, that is, the N-Si-O vibration band became dominant, while the $\mathrm{C}-\mathrm{Si}-\mathrm{O}$ vibration band significantly weakened as the $\mathrm{NH}_{3}$ flow rate increased to $5 \mathrm{sccm}$. This result indicated that the dominant phase in the films changed from silicon oxycarbide to silicon oxynitride when the $\mathrm{NH}_{3}$ flow rate increased to $5 \mathrm{sccm}$.



Figure 5. The atom concentration of $\mathrm{Si}, \mathrm{C}, \mathrm{O}$, and $\mathrm{N}$ of the $\mathrm{SiCO}: \mathrm{N}$ films against the $\mathrm{NH}_{3}$ flow rates.

The PL decay analysis (Figure 3) revealed that the luminescent dynamic behavior in the nitrogen doped $\mathrm{SiC}_{\mathrm{x}} \mathrm{O}_{\mathrm{y}}$ films featured a defect-related luminescent characteristic, as observed in $\mathrm{SiN}_{\mathrm{x}} \mathrm{O}_{\mathrm{y}}$ and $\mathrm{SiC}_{\mathrm{x}} \mathrm{O}_{\mathrm{y}}$ films. Previous studies clarified that C-related nonbridging oxygen hole centers (NBOHC) are the principal radiative recombination centers in silicon oxycarbide, and they are responsible for light emission ranging from the green region to the red region [28]. In our case, the PL intensity in the film decreased as the $\mathrm{NH}_{3}$ flow rate increased. This change was similar to that of the intensity of the $\mathrm{C}-\mathrm{Si}-\mathrm{O}$ bonds (Figure 4). Therefore, the observed tunable light emissions from green to red may have originated from recombination through $\mathrm{C}$-related $\mathrm{NBOHC}$ defects in $\mathrm{SiC}_{\mathrm{x}} \mathrm{O}_{\mathrm{y}}$ films. The PL spectra of the S3 film could be deconvoluted into a strong green band and a weak blue band. As the $\mathrm{NH}_{3}$ flow rate increased to $5 \mathrm{sccm}$, the intensity of the green PL band decreased dramatically, whereas the blue PL band of the film S4 became dominant. This behavior could be attributed to the change in the dominant phase of the films from silicon oxycarbide to silicon oxynitride as a result of the increase in $\mathrm{NH}_{3}$ flow rate to $5 \mathrm{sccm}$ (Figure 4). In the case of amorphous $\mathrm{SiN}_{\mathrm{x}} \mathrm{O}_{\mathrm{y}}$ films, the blue PL could be ascribed to the radiative recombination between $\mathrm{N}-\mathrm{Si}-\mathrm{O}$ defect states and the valence band tail states [27]. Thus, the blue PL from S3 and S4 was likely from N-Si-O defect luminescent centers.

\section{Conclusions}

In summary, we report the effect of nitrogen doping on the $\mathrm{PL}$ of amorphous $\mathrm{SiC}_{\mathrm{x}} \mathrm{O}_{\mathrm{y}}$ films. Nitrogen doping can induce strong red, orange-yellow, white, and blue switching PL with a recombination lifetime in nanoseconds. This process can also widen the band gap of $\mathrm{SiC}_{\mathrm{x}} \mathrm{O}_{\mathrm{y}}$ films. The PL results and the FTIR analyses reveal that the switching characteristics in PL originate from the variation in defect 
luminescent centers resulting from the chemical bond re-construction as a function of nitrogen doping. Apparently, nitrogen doping provides an alternative route for designing and fabricating tunable and efficient $\mathrm{SiC}_{\mathrm{x}} \mathrm{O}_{\mathrm{y}}$-based luminescent films for the development of Si-based optoelec-tronic devices.

Author Contributions: Data curation, J.S. and Z.L. (Zhenxu Lin); Investigation, Y.Z., Z.L. (Zewen Lin), and H.L.; Methodology, C.S., and Y.G., All authors analyzed the experimental data; Writing-review \& editing, J.S., Z.L. (Zhenxu Lin), R.H. and W.Z.; All authors participated in discussions and knew implications of the work.

Funding: This work was supported by National Natural Science Foundation of China (Nos. 61274140), Natural Science Foundation of Guangdong Province (2015A030313871), Young Talents in Higher Education of Guangdong (2017KQNCX129), the Distinguished Young Teacher Training Program in Higher Education of Guangdong (YQ2015112), Science and Technology Planning Project of Guangdong Province (2017B090921002) and Science and Technology Planning Project of Chaozhou (2018SS24).

Conflicts of Interest: The authors declare no conflict of interest.

\section{References}

1. Pavesi, L.; Negro, L.D.; Mazzoleni, C.; Franzo, G.; Priolo, F. Optical gain in silicon nanocrystals. Nature 2000, 408, 440-444. [CrossRef] [PubMed]

2. Cheng, C.H.; Lien, Y.C.; Wu, C.L.; Lin, G.R. Mutlicolor electroluminescent Si quantum dots embedded in $\mathrm{SiOx}$ thin film MOSLED with 24\% external quantum efficiency. Opt. Express 2013, 21, 391-403. [CrossRef] [PubMed]

3. Li, D.; Wang, F.; Yang, D. Evolution of electroluminescence from silicon nitride light-emitting devices via nanostructural silver. Nanoscale 2013, 5, 3435-3440. [CrossRef] [PubMed]

4. Huang, R.; Lin, Z.; Lin, Z.; Song, C. Suppression of hole overflow and enhancement of light emission efficiency in Si quantum dots based silicon nitride light emitting diodes. IEEE J. Sel. Top. Quantum. Electron. 2014, 20, 212-217. [CrossRef]

5. Limpens, R.; Luxembourg, S.L.; Weeber, A.W.; Gregorkiewicz, T. Emission efficiency limit of Si nanocrystals. Sci. Rep. 2016, 6, 19566. [CrossRef] [PubMed]

6. Yao, L.; Yu, T.; Ba, L.; Meng, H.; Fang, X.; Wang, Y. Efficient silicon quantum dots light emitting diodes with an inverted device structure. J. Mater. Chem. C 2016, 4, 673-677. [CrossRef]

7. Lin, Z.; Chen, K.; Zhang, P.; Xu, J.; Li, W.; Yang, H. Improved power efficiency in phosphorus doped na-SiN $\mathrm{O}_{\mathrm{y}} / \mathrm{p}$-Si heterojunction light emitting diode. Appl. Phys. Lett. 2017, 110, 081109. [CrossRef]

8. Li, M.; Jiang, L.; Sun, Y.; Xiao, T.; Xiang, P.; Tan, X. Silicon content influence on structure and photoluminescence properties of carbon rich hydrogenated amorphous silicon carbide thin films. J. Alloys Compd. 2018, 753, 320-328. [CrossRef]

9. Zhang, X.; Chen, R.; Wang, P.; Gan, Z.; Zhang, Y.; Jin, H.; Jian, J.; Xu, J. Investigation of energy transfer mechanisms in rare earth ions and $\mathrm{SnO}_{2}$ quantum dots co-doped amorphous silica films. Opt. Express 2019, 27, 2783-2791. [CrossRef]

10. Ding, Y.; Shirai, H. White light emission from silicon oxycarbide films prepared by using atmospheric pressure microplasma jet. J. Appl. Phys. 2009, 105, 043515. [CrossRef]

11. Tabassum, N.; Nikas, V.; Ford, B.; Huang, M.; Kaloyeros, A.E.; Gallis, S. Time-resolved analysis of the white photoluminescence from chemically synthesized $\mathrm{SiC}_{\mathrm{x}} \mathrm{O}_{\mathrm{y}}$ thin films and nanowires. Appl. Phys. Lett. 2016, 109, 043104. [CrossRef]

12. Bellocchi, G.; Iacona, F.; Miritello, M.; Cesca, T.; Franzò, G. SiOC thin films: An efficient light source and an ideal host matrix for $\mathrm{Eu}^{2+}$ ions. Opt. Express 2013, 21, 20280-20290. [CrossRef] [PubMed]

13. Lin, Z.; Huang, R.; Wang, H.; Wang, Y.; Zhang, Y.; Guo, Y. Dense nanosized europium silicate clusters induced light emission enhancement in Eu-doped silicon oxycarbide films. J. Alloys Compd. 2017, 694, 946-951. [CrossRef]

14. Ding, Y.; Shirai, H.; He, D. White light emission and electrical properties of silicon oxycarbide-based metal-oxide-semiconductor diode. Thin Solid Films 2011, 519, 2513-2515. [CrossRef]

15. Lin, Z.; Huang, R.; Zhang, Y.; Song, J.; Li, H.; Guo, Y.; Song, C. Defect emission and optical gain in $\mathrm{SiC}_{\mathrm{x}} \mathrm{O}_{\mathrm{y}}: \mathrm{H}$ films. ACS Appl. Mater. Interfaces 2017, 9, 22725-22731. [CrossRef]

16. Gallis, S.; Huang, M.; Kaloyeros, A.E. Efficient energy transfer from silicon oxycarbide matrix to Er ions via indirect excitation mechanisms. Appl. Phys. Lett. 2007, 90, 161914. [CrossRef] 
17. Bellocchi, G.; Franzò, G.; Miritello, M.; Iacona, F. White light emission from Eu-doped SiOC films. Appl. Phys. Express 2013, 7, 012601. [CrossRef]

18. Bellocchi, G.; Fabbri, F.; Miritello, M.; Iacona, F.; Franzò, G. Multicolor depth-resolved cathodoluminescence from Eu-doped SiOC thin films. ACS Appl. Mater. Interfaces 2015, 7, 18201-18205. [CrossRef]

19. Lin, Z.; Guo, Y.; Song, J.; Zhang, Y.; Song, C.; Wang, X. Effect of thermal annealing on the blue luminescence of amorphous silicon oxycarbide films. J. Non-Cryst. Solids 2015, 428, 184-188. [CrossRef]

20. Rui, Y.; Li, S.; Xu, J.; Song, C.; Jiang, X.; Li, W. Size-dependent electroluminescence from Si quantum dots embedded in amorphous SiC matrix. J. Appl. Phys. 2011, 110, 064322. [CrossRef]

21. Huang, R.; Lin, Z.; Guo, Y.; Song, C.; Wang, X.; Lin, H. Bright red, orange-yellow and white switching photoluminescence from silicon oxynitride films with fast decay dynamics. Opt. Mater. Express 2014, 4, 205-212. [CrossRef]

22. Kato, H.; Kashio, N.; Ohki, Y.; Seol, K.S.; Noma, T. Band-tail photoluminescence in hydrogenated amorphous silicon oxynitride and silicon nitride films. J. Appl. Phys. 2003, 93, 239-244. [CrossRef]

23. Huang, R.; Wang, X.; Song, J.; Guo, Y.; Ding, H.; Wang, D. Strong orange-red light emissions from amorphous silicon nitride films grown at high pressures. Scripta Mater. 2010, 62, 643-645. [CrossRef]

24. Grill, A.; Neumayer, D.A. Structure of low dielectric constant to extreme low dielectric constant SiCOH films: Fourier transform infrared spectroscopy characterization. J. Appl. Phys. 2003, 94, 6697-6707. [CrossRef]

25. Yao, R.; Feng, Z.; Zhang, B.; Zhao, H.; Yu, Y.; Chen, L. Blue photoluminescence from continuous freestanding $\beta-\mathrm{SiC} / \mathrm{SiO}_{\mathrm{x}} \mathrm{C}_{\mathrm{y}} / \mathrm{C}$ free nanocomposite films with polycarbosilane (pcs) precursor. Opt. Mater. 2011, 33, 635-642. [CrossRef]

26. Wang, J.; Suendo, V.; Abramov, A.; Yu, L.; Pere, R.I.C. Strongly enhanced tunable photoluminescence in polymorphous silicon carbon thin films via excitation-transfer mechanism. Appl. Phys. Lett. 2010, 97, 221113. [CrossRef]

27. Zhang, P.; Chen, K.; Lin, Z.; Tan, D.; Dong, H.; Li, W. Dynamics of high quantum efficiency photoluminescence from N-Si-O bonding states in oxygenated amorphous silicon nitride films. Appl. Phys. Lett. 2016, 118, 111103. [CrossRef]

28. Gallis, S.; Nikas, V.; Suhag, H.; Huang, M.; Kaloyeros, A.E. White light emission from amorphous silicon oxycarbide $\left(\mathrm{a}-\mathrm{SiC}_{\mathrm{x}} \mathrm{O}_{\mathrm{y}}\right)$ thin films: Role of composition and postdeposition annealing. Appl. Phys. Lett. 2010, 97, 081905. [CrossRef] 